\title{
Marking Basilar Artery Using Neuronavigation During Endoscopic Third Ventriculostomy: A Clinical Study
}

\author{
Onur OZGURAL ${ }^{1}$, Gokmen KAHILOGULLARI ${ }^{1}$, Giuseppe CINALLI², Umit EROGLU1 ${ }^{1}$, Ihsan DOGAN', \\ Eyyub S M AL-BEYATI'1, Murat ZAIMOGLU'1, Agahan UNLU'
}

\author{
${ }^{1}$ Ankara University School of Medicine, Department of Neurosurgery, Ankara, Turkey \\ ${ }^{2}$ University of Naples Federico II, Santobono Pausilipon Hospital, Department of Neurosurgery, Naples, Italy
}

Corresponding author: Onur OZGURAL onurozgural@yahoo.com

\section{ABSTRACT}

AIM: To evaluate the efficacy of using a neuronavigation system for demonstrating the relationship between the basilar artery (BA) and ventricular floor during endoscopic third ventriculostomy (ETV).

MATERIAL and METHODS: Records of 28 patients (16 females and 12 males) diagnosed with obstructive hydrocephalus who had undergone a neuroendoscopic procedure were retrospectively examined. Patient age ranged from 1 to 76 years (median 24.46 years). The BA was marked with using the neuronavigation system in all cases to visualise its relationship to the floor of the third ventricle in real time.

RESULTS: ETV was successfully performed in 28 patients with obstructive hydrocephalus. Of these, 13 (46.4\%) patients had a thickened tuber cinereum (TC) membrane and 3 (10.7\%) showed lateralization of the BA under the ventricular floor. No contact with the BA or related complications (e.g., major bleeding) was encountered with BA marking by using neuronavigation.

CONCLUSION: Even though thickening of the TC membrane and/or displacement of the BA might be seen otherwise, we describe a new method that combines marking the BA and using neuronavigation to provide greater safety in the area where the ventriculostomy will be performed. This permits clearer orientation for the surgeon which significantly contributes to minimizing surgical morbidity.

KEYWORDS: Basilar artery, Endoscopic, Neuronavigation, Tuber cinereum, Ventriculostomy

\section{INTRODUCTION}

$\mathrm{N}$ euroendoscopic surgery is routinely used not only during third ventriculostomy but also during procedures such as cyst fenestration, complex hydrocephalus and tumour biopsy $(4,9,19,22,24,36)$. Such increased use also increases complication rates due to neuroendoscope use, e.g., wrong direction or damage due to the endoscope's direct mechanical impact (25). Therefore, the entire neuroendoscopic procedure from the preoperative period to removal of endoscope after washing- should be well-planned $(23,26)$. Minor haemorrhages may be seen during endoscopic third ventriculostomy (ETV) which usually stop after washing, but major bleeding from the basilar artery (BA) or its branches can result in serious complications and are associated high morbidity and mortality. Therefore, it is essential to obtain precise fenestration in the floor of the ventricle without injuring the BA, and a ventriculostomy is generally performed in the safe zone described before, which is the area between the infundibular recess and in front of the mammillary bodies $(14,27,38,41)$. Nonetheless, anatomical variations in the BA and its branches have been described in the past decade, and other at-risk situations during ETV include the absence of a translucent TC which prevents endoscopic visualisation and localization of the arteries, especially in the elderly $(31,34)$. Integration of neuronavigation during neuroendoscopic procedures can result in a safer procedure with real-time visualisation during

\footnotetext{
Onur OZGURAL

(D) : 0000-0001-5797-4373

Umit EROGLU

(D) : 0000-0001-8623-071X

Murat ZAIMOGLU (D) : 0000-0001-5330-1251

Gokmen KAHILOGULLARI

(D) : 0000-0001-8137-0510

Ihsan DOGAN

(D) : 0000-0002-1985-719X

Giuseppe CINALL

(D) : 0000-0002-7797-8483

Eyyub S M AL-BEYATI (D) : 0000-0001-6246-4247

(D) : 0000-0002-2039-8592
} 
ETV. Here, we have evaluated the effectiveness of using a 'navigation-guided safe fenestration zone' by marking the BA in patients undergoing ETV.

\section{MATERIAL and METHODS}

\section{Patients and Preoperative Assessment}

Medical records of 28 patients diagnosed with obstructive hydrocephalus who had undergone the ETV procedure were retrospectively reviewed. Patient consent form was taken from all patients (form was taken from parents who were under 18 ages). Exclusion criteria included previous ETV procedures, shunt placement, diagnosed complex hydrocephalus, or presence of intraventricular tumours. Three-dimensional gradient-echo (3D-GRE) MR images, acquired at slide thickness of 1 milimeter $(\mathrm{mm})$, were transferred to the neuronavigational system workstation for reconstruction of a three-dimensional model of the patient's head and brain. Neuronavigation used the Brainlab ${ }^{\circledR}$ Cranial 3.0 system. Burr holes to be opened were identified at the classic Kocher's point and their placement was controlled using navigation before the incision was made (Figure 1). A head frame (Mayfield) was used in all patients as part of the navigation system, except in four infants less than 2 years old. The BA was marked using in every patient and was used to reveal the 'neuro-guided safe zone' during fenestration, based on the position of the BA.

\section{Surgical Procedure}

Slightly curved incisions were made in the skin and the periosteum and burr holes opened using curved front and back movements such that the trocar could fit (Figure 2). The brain needle was introduced using the navigation system in order to minimise the error margin during initial entry (Figure 3). Variable size of trocar (2.5-5.5 mm) was selected based on previous calculations on MRI. Next, 0-degrees rigid neuroendoscope (The Little Lotta ${ }^{\circledR}$, Karl Storz SE \& Co. KG, Tuttlingen, Germany was inserted into the ventricle under neuronavigation guidance (Figure 4). Next, using neuronavigation, after entering the third ventricle, the floor and the position of the BA were identified and the relationship between artery and TC was established. If a thickened TC and/or displacement of BA were observed, the hole in the ventricle floor was made in the safe area without any major artery, as determined using the navigation system. After completion of the ventriculostomy, the intraventricular region was irrigated for 2-3 minutes and the procedure was completed. The entire procedure lasted between 9-14 minutes for all patients.

\section{RESULTS}

Of the 28 patients, 12 were male and 16 were female. Patients' ages ranged between 1-76 years with mean age of 24.46 years; 12 patients were less than 18 years old while 16 patients were older than 18 years. Twenty-four of the 28 patients diagnosed with obstructive hydrocephalus had symptoms of headaches, dizziness, blurred vision, and gait disorder, while 4 patients who were 2 years old or younger presented with discomfort, increase in head circumference, and fontanelle tension. Table I lists patient demographics such as age, gender, symptoms, and complications. The TC was seen as a thick membrane in 13 cases (46.7\%; five males and eight females; Figures 5 $A, B)$, while lateral displacement of the BA was seen in three patients (10.7\%; two females and one male). Neuronavigation was particularly helpful in these 16 patients as the BA and the area of ventriculostomy could be effectively identified (Figure 6). Table II shows the relationship between BA and TC. That was observable as mild haemorrhage in two patients during the intraoperative period; they were controlled by washing. No contact with the BA or related complications (e.g., major bleeding) occurred under neuronavigation guidance and there were no mortalities.

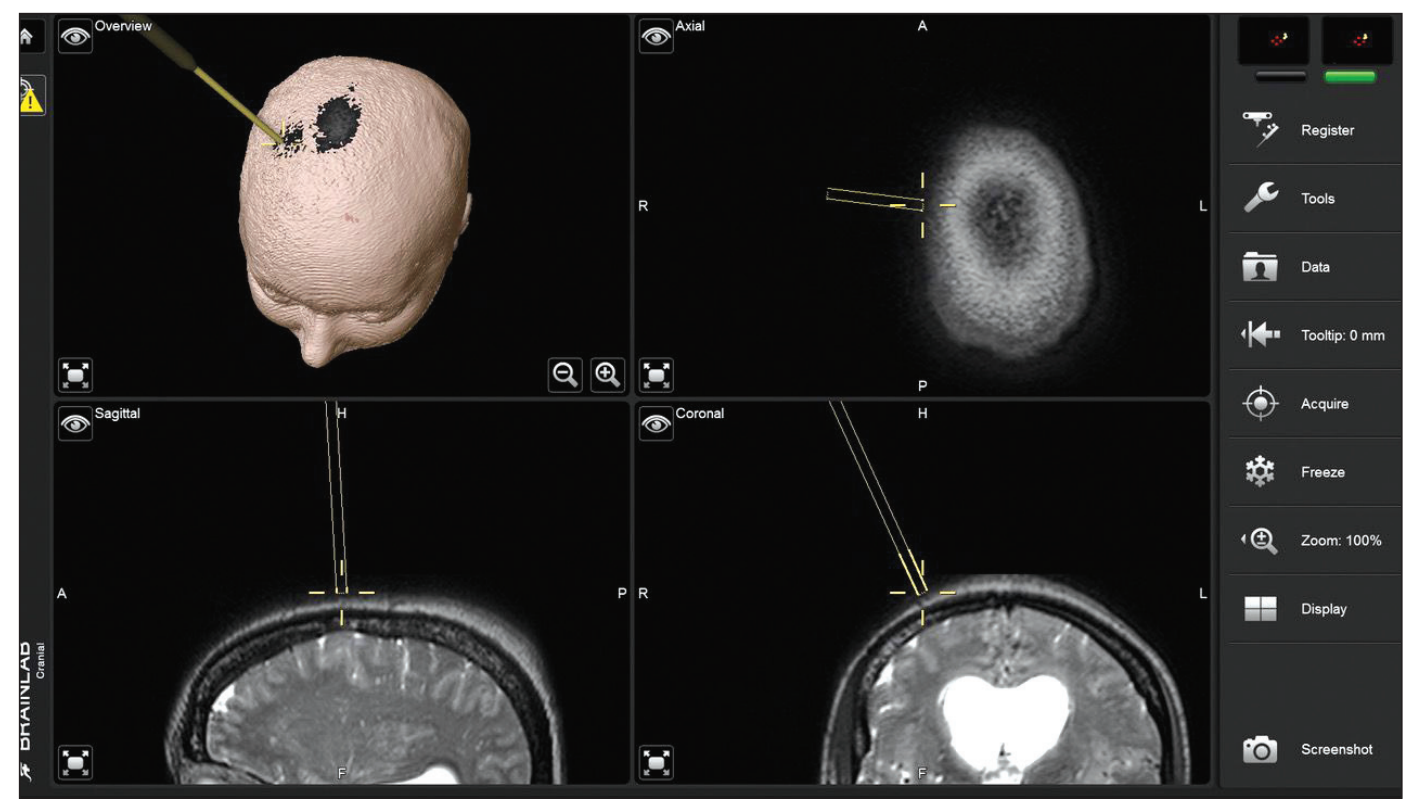

Figure 1: A direct route to the lateral ventricle using the navigation system on MRI. 


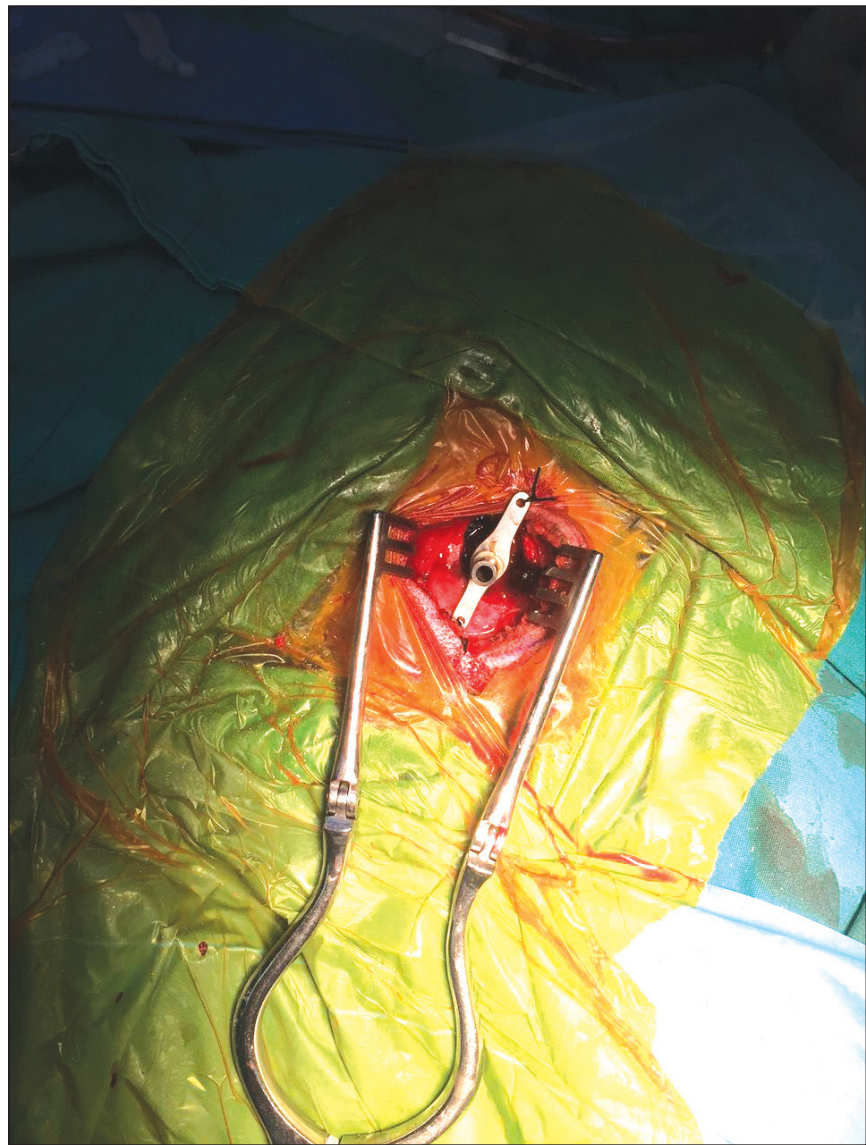

Figure 2: After skin incision and replacement of trocar.

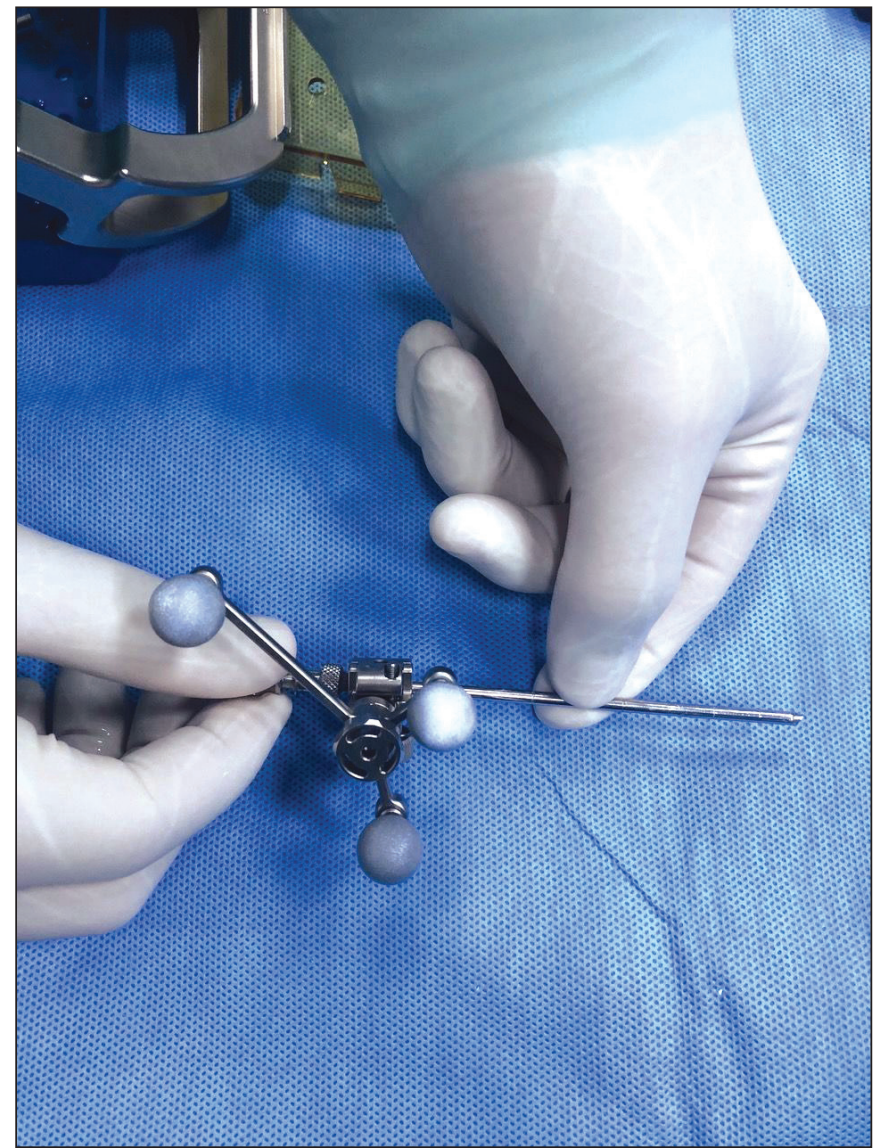

Figure 3: Brain needle with the navigation antenna.

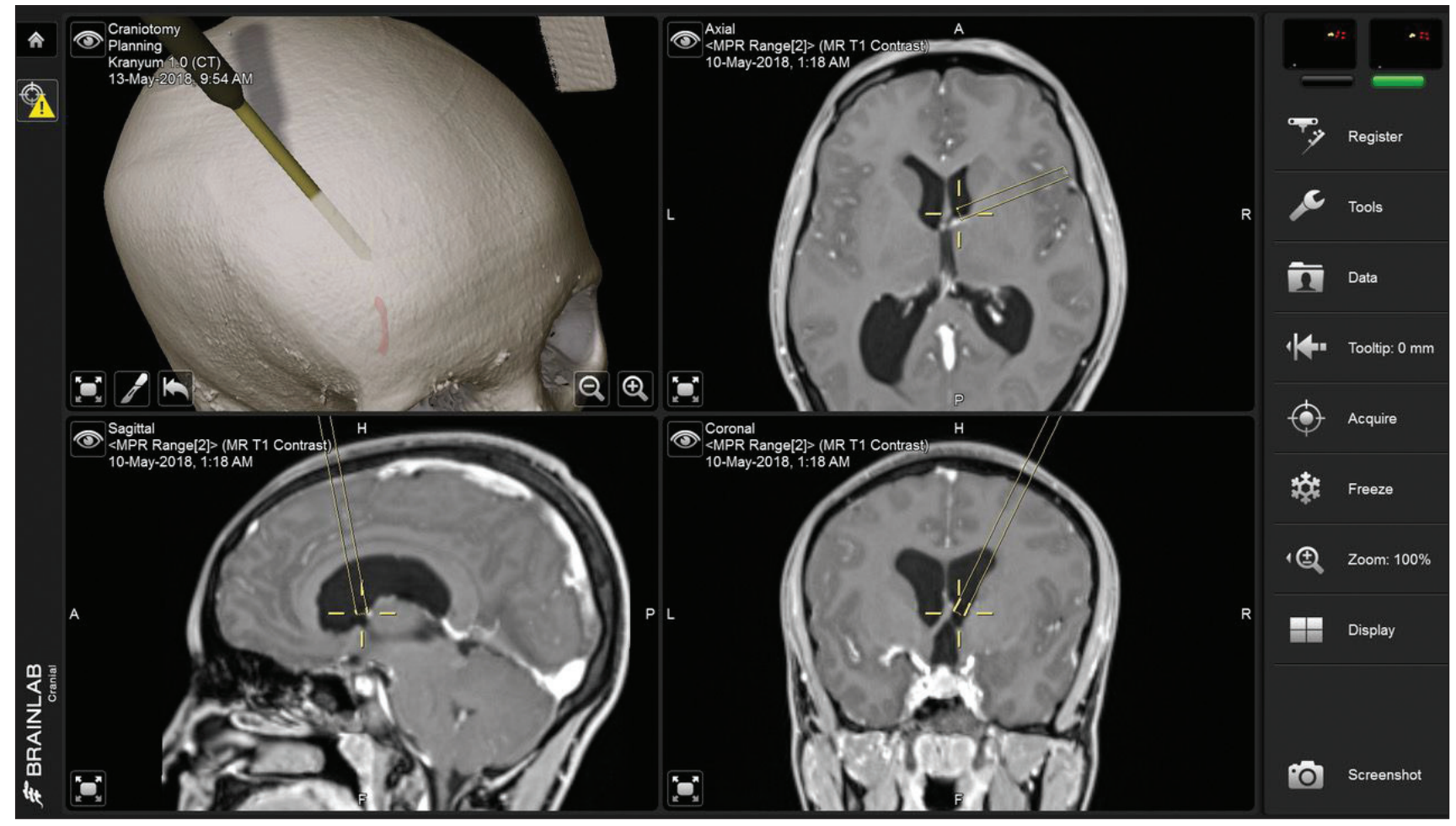

Figure 4: Neuronavigation shows the endoscope after entry in to the ventricle. 
Table I: Demographic and Clinical Features of the Patients, and Surgical Complications

\begin{tabular}{|c|c|c|c|c|}
\hline $\begin{array}{c}\text { Patient } \\
\text { No }\end{array}$ & Age & Sex & Symptom & Complication \\
\hline 1 & 44 & $\mathrm{~F}$ & $\mathrm{HA}$ & - \\
\hline 2 & 43 & $\mathrm{~F}$ & HA, GD & Mild hemorrhage \\
\hline 3 & 1 & $\mathrm{M}$ & $\mathrm{FT}, \mathrm{IHC}$ & CSF leakage \\
\hline 4 & 28 & $\mathrm{~F}$ & $\mathrm{HA}$ & - \\
\hline 5 & 36 & M & $\mathrm{HA}, \mathrm{BV}$ & - \\
\hline 6 & 76 & $M$ & $\mathrm{HA}, \mathrm{GD}, \mathrm{D}$ & - \\
\hline 7 & 25 & $\mathrm{~F}$ & $\mathrm{HA}$ & - \\
\hline 8 & 2 & $\mathrm{~F}$ & FT, IHC & - \\
\hline 9 & 20 & $\mathrm{~F}$ & $\mathrm{HA}$ & Mild hemorrhage \\
\hline 10 & 32 & $M$ & $\mathrm{HA}, \mathrm{BV}$ & - \\
\hline 11 & 64 & $\mathrm{~F}$ & $\mathrm{HA}, \mathrm{GD}, \mathrm{D}$ & - \\
\hline 12 & 17 & $M$ & $\mathrm{HA}$ & - \\
\hline 13 & 20 & $M$ & $\mathrm{HA}$ & - \\
\hline 14 & 13 & $\mathrm{~F}$ & $\mathrm{HA}, \mathrm{BV}$ & - \\
\hline 15 & 10 & M & $\mathrm{HA}$ & - \\
\hline 16 & 55 & $\mathrm{M}$ & $\mathrm{HA}, \mathrm{GD}, \mathrm{BV}$ & - \\
\hline 17 & 1 & $\mathrm{~F}$ & $\mathrm{FT}, \mathrm{IHC}$ & CSF leakage \\
\hline 18 & 1 & $M$ & FT, IHC & - \\
\hline 19 & 5 & $M$ & $\mathrm{HA}$ & - \\
\hline 20 & 25 & $\mathrm{~F}$ & $\mathrm{HA}, \mathrm{GD}, \mathrm{D}$ & - \\
\hline 21 & 8 & $\mathrm{~F}$ & $\mathrm{HA}, \mathrm{BV}$ & - \\
\hline 22 & 9 & $\mathrm{~F}$ & $\mathrm{HA}$ & - \\
\hline 23 & 42 & $\mathrm{~F}$ & $\mathrm{HA}, \mathrm{GD}, \mathrm{D}$ & - \\
\hline 24 & 25 & $\mathrm{M}$ & $\mathrm{HA}, \mathrm{GD}$ & - \\
\hline 25 & 6 & $\mathrm{~F}$ & $\mathrm{HA}$ & - \\
\hline 26 & 39 & $\mathrm{~F}$ & $\mathrm{HA}, \mathrm{BV}$ & - \\
\hline 27 & 20 & $\mathrm{M}$ & $\mathrm{HA}, \mathrm{D}$ & - \\
\hline 28 & 18 & $\mathrm{~F}$ & $H A, D$ & - \\
\hline
\end{tabular}

F: Female, M: Male, HA: Headache, GD: Gait disturbance, D: Dizziness, BV: Blurred vision, FT: Fontanelle tension, IHC: Increased head circumference, CSF: Cerebrospinal fluid.

Table II: Numbers of Thickened Tuber Cinereum and Displaced Basilar Artery

\begin{tabular}{lccc}
\hline Gender & Thickened TC & Displaced BA & Total \\
\hline Male & 5 & 1 & $6 / 12$ \\
\hline Female & 8 & 2 & $10 / 16$ \\
\hline
\end{tabular}

BA: Basilar artery, TC: tuber cinereum.

\section{DISCUSSION}

The use of neuronavigation systems began in the early 2000 s and technological improvements since then have increased accuracy rates and safety profile of the procedures, thereby positively affecting prognosis among patients undergoing neurosurgery $(1,13)$. Initially, neuronavigation was used in microscopic transcranial procedures, and as experience was gained, it was adapted for use in transsphenoidal endoscopic procedures $(8,40)$. The use of neuronavigation in intraventricular surgical procedures for hydrocephalus and arachnoid cysts has only recently increased and has been shown to be highly beneficial in patients with particularly complex anatomy $(12,20,35,39)$. We show that it is possible to provide direct and straight entry into the ventricle during the first phase of the procedure by introducing the navigation system to the brain needle. Such a manoeuvre is particularly advantageous in patients with asymmetrical ventricle anatomy. Similar to our experience described here, McMillen et al. have reported that neuronavigation systems were beneficial when used for neuroendoscopic procedures performed on 19 paediatric patients with abnormal ventricular anatomy (28). Hermann et al. have shown that navigation system use was helpful and reliable during electromagnetically-navigated neuroendoscopic procedures in 22 paediatric patients (15). However, in this study, we used head frame fixation rather than a horseshoe headrest, except in patients who were less than 2 years old. In doing so, we eliminated any potential deviation in navigation due to possible movement of the patient. However, unlike the two studies mentioned above, we used neuronavigation as a 'safe zone guide' to the floor of the third ventricle floor by marking the BA to avoid major arterial injury.

It is known that the optimal fenestration area in the third ventricle is in the middle of the floor $(14,29,41)$. Brockmeyer has signified that this should be at a point just anterior to the midpoint between the mamillary body and the infundibular recess (5). Posterior fenestration from this point onwards can result in encountering the BA or its major branches. Therefore, entering a little anterior to the midpoint is safer than entering more posteriorly (5). Although there is a translucent area called the 'safe zone' in the middle of the TC, Vinas et al. have emphasised that even a very small midline fenestration can cause BA injury, and several studies have identified contact with the tip of the neuroendoscope, laser, or coagulation wire as the major etiological factors of basilar injury $(6,16,27,37,41)$. However, Yildirim et al. reported a case with higher BA location and a thick Lillequist Membrane may have tragic consequences but achieved to make a hole at the floor by retracting BA (43). Given this, it is important to mention here that we used neuronavigation-guided fenestration, where in the BA and its association with the ventricular floor could be visualised in a real time to avoid major arterial bleeding, especially in patients with unusual anatomy.

It is essential and highly important that neuroendoscopic procedures where in the skull is penetrated through a small hole not result in any neural and/or vascular damage while reaching the targeted area $(7,30)$. Therefore, it is better to 

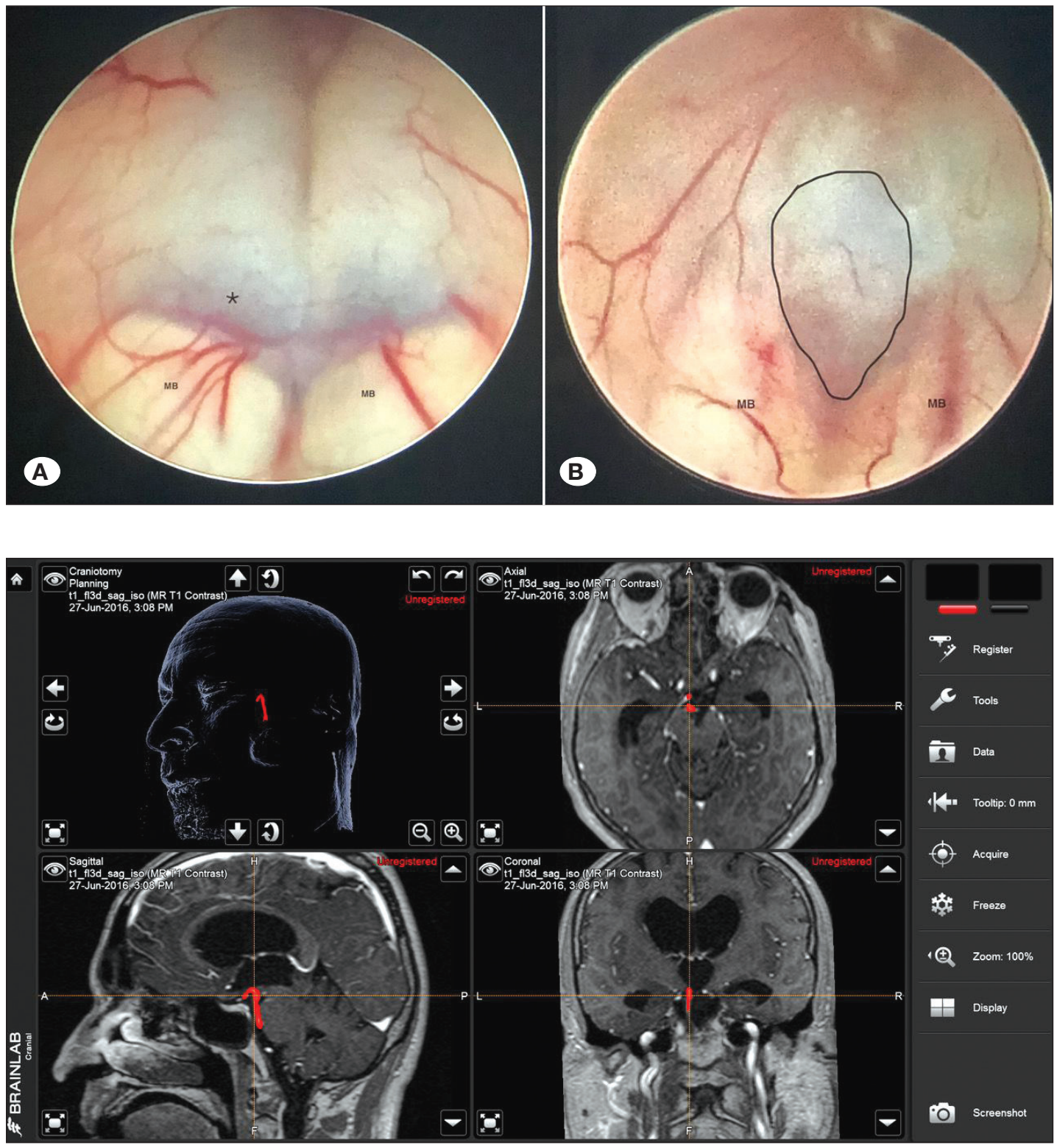

Figure 5:

A) Intraoperative neuroendoscopic view of thick-blurred tuber cinereum (MB: mamillary body, asterisk (*): displaced basilar artery).

B) Intraoperative neuroendoscopic view of thick-blurred tuber cinereum (black circle: area of thickened membrane) abandon the procedure if there is disorientation, a higher risk of complications such as bleeding, or a thick and opaque ventricular floor without clear visualisation of the anatomy (42). By marking the BA using the navigation system, we achieved greater reliability during routine ventriculostomy procedures. To the best of our knowledge, this is different from the surgical procedures described in literature. Importantly, there was no significant morbidity during the ETV procedure and the minor bleeding in two patients could be controlled by washing.

We were able to easily orient and find the area to be fenestrated because the BA under the TC and its relationship to the floor were visible in real time. This modification will be significant, especially in patients who have a thickened membrane with BA displacement (Figures 7A, B). Thickening of the TC in hydrocephalic patients is not an uncommon anomaly, and especially in long standing hydrocephalus, it may occur a dense membrane by existing type I collagen (11). Therefore, the risk of damage to the BA and the small arteries of the TC is also thought to be higher as they are often not visible through the opaque floor (18). Rohde and Gilsbach have reported a $16 \%$ incidence of in 25 hydrocephalic patients (33), while laccarino et al. found it in 11 of 23 (48\%) ETV patients (18). Another study, Etus et al. found $33.1 \%$ thickened membrane between 455 meningomyelocele patient who were performed ETV (10). In our study, 13 patients (46.7\%) had a thickened membrane such that the BA could not be visualised.

As mentioned above, an important complication of neuroendoscopic procedures is bleeding and the most concerning is that from the BA and its branches (17). The rate of bleeding ranges between $0-8.5 \%$ with reported significant bleeding rate of $4 \%$ and basilar type bleeding rate of $0.2 \%(2,3,21,32)$. Horsburgh et al. have analysed axial MR images and state that 

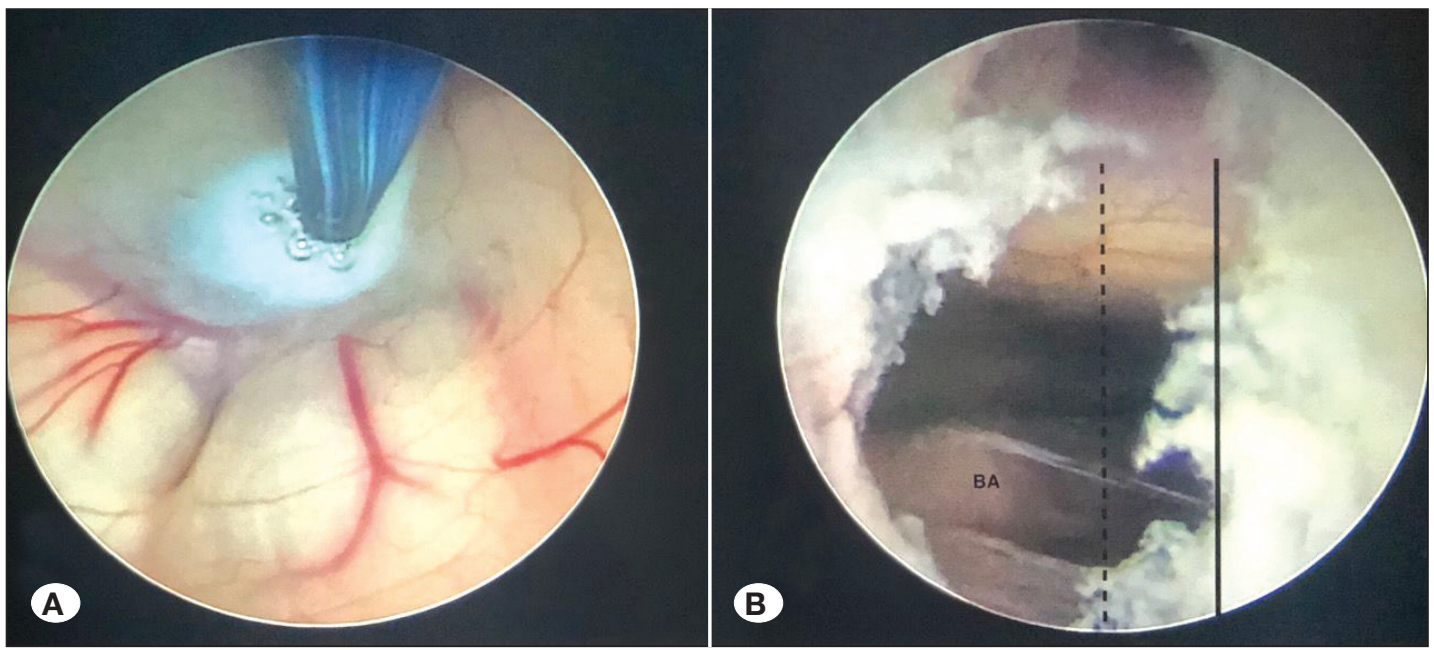

Figure 7: A) Navigationguided safe zone area, entry pint selected to avoid injury to the leftsided basilar artery B) Left-sided basilar artery seen after fenestration, black dotted line shows the midline of floor, black line shows where fenestration had begun on to the floor (BA: Basilar artery).

in $12 \%$ of the patients, the basilar tip was in close proximity to the mamillary bodies, and that it was located either in front, under, or behind. Additionally, midsagittal MRI views showed that in $10 \%$ of the patients, the BA either touched or was within $1 \mathrm{~mm}$ of the under-surface of the TC; such a position carries significant risk of potential injury during ETV (17). Another study by Zhang et al. that included $162 \mathrm{MRI}$ angiography images found that displacement of the BA was seen more frequently in men than in women and that it increased with age (44). In contrast, two of the three patients with BA displacement were female in our series. Thus, as it is apparent that ETV in patients with displacement of the BA and its branches is risky, such risk can be eliminated as much as possible by visualising the BA and its branches in real time during the procedure.

Despite the above, there are a few limitations to this study. The small sample size is one, but comparative studies with a greater number of patients will help verify the observations made here. One of the disadvantages of the ETV procedure is prolonged procedure time because the surgeon holds the neuroendoscope with one hand and any increase in tremor would lead to higher morbidity rates. Thus, it is important to perform the procedure without any disruptions and with the entire team functioning flawlessly.

\section{CONCLUSION}

We suggest that marking the BA by using neuronavigation during ETV can help in identifying the 'navigation-guided safe zone', especially in patients with thickened TC and/or displaced BA anatomy, as it provides better orientation and a superior safety profile.

\section{ACKNOWLEDGEMENTS}

Preparation for publication of this article is partly supported by Turkish Neurosurgical Society.

\section{REFERENCES}

1. Alberti $\mathrm{O}$, Riegel $\mathrm{T}$, Hellwig $\mathrm{D}$, Bertalanffy $\mathrm{H}$ : Frameless navigation and endoscopy. J Neurosurg 95:541-543, 2001

2. Amini $A$, Schmidt $\mathrm{RH}$ : Endoscopic third ventriculostomy in a series of 36 adult patients. Neurosurg Focus 19:E9, 2005

3. Bilginer $\mathrm{B}$, Oguz $\mathrm{KK}$, Akalan $\mathrm{N}$ : Endoscopic third ventriculostomy for malfunction in previously shunted infants. Childs Nerv Syst 25:683-688, 2009

4. Boschert J, Hellwig D, Krauss JK: Endoscopic third ventriculostomy for shunt dysfunction in occlusive hydrocephalus: Long-term follow up and review. J Neurosurg 98:1032-1039, 2003

5. Brockmeyer D: Techniques of endoscopic third ventriculostomy. Neurosurg Clin N Am 15:51-59, 2004

6. Buxton N, Punt J: Cerebral infarction after neuroendoscopic third ventriculostomy: Case report. Neurosurgery 46:9991001,2000

7. Constantini S, Mohanty A, Zymberg S, Cavalheiro S, Mallucci C, Hellwig D, Ersahin Y, Mori H, Mascari C, Val JA, Wagner W, Kulkarni AV, Sgouros S, Oi S: Safety and diagnostic accuracy of neuroendoscopic biopsies: An international multicenter study. J Neurosurg Pediatr 11:704-709, 2013

8. Eboli P, Shafa B, Mayberg M: Intraoperative computed tomography registration and electromagnetic neuronavigation for transsphenoidal pituitary surgery: Accuracy and time effectiveness. J Neurosurg 114:329-335, 2011

9. El-Ghandour NM: Endoscopic treatment of intraparenchymal arachnoid cysts in children. J Neurosurg Pediatr 14:501-507, 2014

10. Etus V, Guler TM, Karabagli $\mathrm{H}$ : Third ventricle floor variations and abnormalities in myelomeningocele associated hydrocephalus: Our experience with 455 endoscopic third ventriculostomy procedures. Turk Neurosurg 27(5):768-771, 2017

11. Etus V, Solakoglu S, Ceylan S: Ultrastructural changes in the Liliequist membrane in the hydrocephalic process and its implications for the endoscopic third ventriculostomy procedure. Turk Neurosurg 21(3):359-366, 2011

12. Fiorindi A, Delitala A, Francaviglia $N$, Longatti $P$ : Neuroendoscopic options in the treatment of mesencephalic expanding cysts: Report of four cases and review of the literature. Clin Neurol Neurosurg 115:2370-2376, 2013 
Ozgural O. et al: Marking Basilar Artery Using Neuronavigation

13. Golfinos JG, Fitzpatrick BC, Smith LR, Spetzler RF: Clinical use of a frameless stereotactic arm: Results of 325 cases. J Neurosurg 83:197-205, 1995

14. Hayashi N, Endo S, Hamada H, Shibata T, Fukuda O, Takaku A: Role of preoperative midsagittal magnetic resonance imaging in endoscopic third ventriculostomy. Minim Invasive Neurosurg 42:79-82, 1999

15. Hermann EJ, Esmaeilzadeh M, Ertl P, Polemikos M, Raab $P$, Krauss JK: Endoscopic intracranial surgery enhanced by electromagnetic-guided neuronavigation in children. Childs Nerv Syst 31:1327-1333, 2015

16. Hopf NJ, Grunert P, Fries G, Resch KD, Perneczky A: Endoscopic third ventriculostomy: Outcome analysis of 100 consecutive procedures. Neurosurgery 45:957-959, 1999

17. Horsburgh A, Matys T, Kirollos RW, Massoud TF: Tuber cinereum proximity to critical major arteries: A morphometric imaging analysis relevant toendoscopic third ventriculostomy. Acta Neurochir (Wien) 155:891-900, 2013

18. laccarino C, Tedeschi E, Rapanà A, Massarelli I, Belfiore G, Quarantelli M, Bellotti A: Is the distance between mammillary bodies predictive of a thickened third ventricle floor? J Neurosurg 110:852-857, 2009

19. Karabatsou K, Hayhurst C, Buxton N, O’Brien DF, Mallucci CL: Endoscopic management of arachnoid cysts: An advancing technique. J Neurosurg 106:455-462, 2007

20. Kim K, Yeon JY, Seol HJ, Shin HJ: Transventricular endoscopic biopsy of suprasellar tumors: A pediatric case series. Childs Nerv Syst 29:1285-1291, 2013

21. Kim SK, Wang KC, Cho BK: Surgical outcome of pediatric hydrocephalus treated by endoscopic III ventriculostomy: Prognostic factors and interpretation of postoperative neuroimaging. Childs Nerv Syst 16:161-168, 2000

22. Kinfe TM, Capelle HH, Mirzayan MJ, Boschert J, Weigel $\mathrm{R}$, Krauss JK: Stereotactic versus endoscopic surgery in periventricular lesions. Acta Neurochir (Wien) 153:517-526, 2011

23. Knaus H, Matthias S, Koch A, Thomale UW: Single burrhole endoscopic biopsy with third ventriculostomy-measurements and computer-assisted planning. Childs Nerv Syst 27:12331241, 2011

24. Kulkarni AV, Sgouros S, Constantini S, Investigators I: International infant hydrocephalus study: Initial results of a prospective, multicenter comparison of endoscopic third ventriculostomy (ETV) and shunt for infant hydrocephalus. Childs Nerv Syst 32(6):1039-1048, 2016

25. Luther N, Cohen A, Souweidane MM: Hemorrhagic sequelae from intracranial neuroendoscopic procedures for intraventricular tumors. Neurosurg Focus 19:E9, 2005

26. Martínez-Moreno M, Widhalm G, Mert A, Kiesel B, Bukaty A, Furtner J, Reinprecht A, Knosp E, Wolfsberger S: A novel protocol of continuous navigation guidance for endoscopic third ventriculostomy. Neurosurgery 10 Suppl 4:514-523, 2014

27. McLaughlin MR, Wahlig JB, Kaufmann AM, Albright AL: Traumatic basilar aneurysm after endoscopic third ventriculostomy: Case report. Neurosurgery 41:1400-1404, 1997

28. McMillen JL, Vonau M, Wood MJ: Pinless frameless electromagnetic image-guided neuroendoscopy in children. Childs Nerv Syst 26:871-878, 2010
29. Oka K, Go Y, Kin Y, Tomonaga M: An observation of the third ventricle under flexible fiberopticventriculoscope: Normal structure. Surg Neurol 40:273-277, 1993

30. Paraskevopoulos D, Biyani N, Constantini S, BeniAdani L: Combined intraoperative magnetic resonance imaging and navigated neuroendoscopy in children with multicompartmental hydrocephalus and complex cysts: A feasibility study. J Neurosurg Pediatr 8:279-288, 2011

31. Peltier J, Fichten A, Page C, Havet E, Foulon P, Mertl P, Le Gars D, Laude M: Endoscopic anatomy of the terminal portion of the basilar artery and its distal perforating branches. Morphologie 92:31-36, 2008

32. Ribaupierre S, Rilliet B, Vernet O, Regli L, Villemure JG: Third ventriculostomy vs ventriculoperitoneal shunt in pediatric obstructive hydrocephalus: Results from a Swiss series and literature review. Childs Nerv Syst 23:527-533, 2007

33. Rohde V, Gilsbach JM: Anomalies and variants of the endoscopic anatomy for third ventriculostomy. Minim Invasive Neurosurg 43:111-117, 2000

34. Romero AC, Aguiar PH, Borchartt TB, Conci A: Quantitative ventricular neuroendoscopy performed on the third ventriculostomy: Anatomic study. Neurosurgery 68 Suppl Operative 2:347-354, 2011

35. Sangra M, Clark S, Hayhurst C, Mallucci C: Electromagnetic guided neuroendoscopy in the pediatric population. J Neurosurg Pediatr 3:325-330, 2009

36. Schroeder HW, Gaab MR, Niendorf WR: Neuroendoscopic approach to arachnoid cysts. J Neurosurg 85:293-298, 1996

37. Schroeder HW, Warzok RW, Assaf JA, Gaab MR: Fatal subarachnoid hemorrhage after endoscopic third ventriculostomy. J Neurosurg 90:153-155, 1999

38. Schroeder HWS, Niendorf WR, Gaab MR: Complications of endoscopic third ventriculostomy. J Neurosurg 96:1032-1040, 2002

39. Schulz M, Bohner G, Knaus H, Haberl H, Thomale UW: Navigated endoscopic surgery for multiloculated hydrocephalus in children. J Neurosurg Pediatr 5:434-442, 2010

40. Sieśkiewicz A, Łysoń T, Mariak Z, Rogowski M: Neuronavigation in transnasal endoscopic paranasal sinuses and cranial base surgery: Comparison of the optical and electromagnetic systems. Otolaryngol Pol 63:256-260, 2009

41. Vinas FC, Dujovny N, Dujovny M: Microanatomical basis for the third ventriculostomy. Minim Invasive Neurosurg 39:116121, 1996

42. Yadav YR, Parihar VS, Ratre S, Kher Y: Avoiding complications in endoscopic third ventriculostomy. J Neurol Surg A Cent Eur Neurosurg 76:483-494, 2015

43. Yildirim AE, Karaoglu D, Divanlioglu D, Belen AD: A difficult endoscopic third ventriculostomy procedure: Perforation of a thick Liliequist membrane with high basilar artery location. Turk Neurosurg 24(6):946-947, 2014

44. Zhang C, Detre JA, Kasner SE, Cucchiara B: Basilar artery lateral displacement may be associated with migraine with aura. Front Neurol 9:80, 2018 